\title{
TRANSFORMAR SIM, PERDER A ESSÊNCIA JAMAIS: O CONTO DE CHAPEUZINHO VERMELHO COMO TEXTO PUBLICITÁRIO
}

\author{
It can change, but never loose the essence: little red hiding hood as a publicitary \\ text
}

\section{Enciende, nunca perder la esencia: el cuento de la caperucita roja como texto del publicidad}

\author{
João Batista Freitas Cardoso ${ }^{1}$ \\ Danuza Pessoa Polistchuk ${ }^{2}$
}

\section{Resumo}

Este estudo apresenta como os contos de fadas, enquanto códigos culturais, podem ser reconhecidos, mesmo com as mudanças sofridas ao longo do tempo, por meio da análise de seis peças publicitárias que têm o conto Chapeuzinho Vermelho como conceito criativo. A partir dos conceitos de texto cultural da semiótica russa e das teorias da imagem de Gombrich foi possível reconhecer como códigos o capuz vermelho e o lobomau e apontar as transformações na narrativa para que se adequasse aos objetivos dos anunciantes.

Palavras-chave: propaganda, conto de fadas, imagem, texto cultural.

\begin{abstract}
This study aims to present how the fairy tales as cultural codes can be recognized, even with the changes undergone over time, by analyzing six advertisements that have the tale Little Red Riding Hood as a creative concept. From the concepts of cultural text of Russian semiotics and the theories of image of Gombrich was possible to recognize as codes the red hood and the bad wolf and to point the transformations in the narrative that were suited to the objectives of advertisers.
\end{abstract}

\footnotetext{
${ }^{1}$ Doutor e mestre em Comunicação e Semiótica pela PUC-SP, com Pós-Doutorado em Comunicação pela ECA-USP. Professor no Programa de Mestrado em Comunicação da USCS. Professor nas universidades Mackenzie e Santa Cecília. Lider do Grupo de Pesquisa "O signo visual nas mídias" (CNPq). E-mail: jbfcardoso@uol.com.br

${ }^{2}$ Mestranda em comunicação, com bolsa Capes, pela Universidade Municipal de São Caetano do Sul (USCS), especialista em marketing pela Fundação Getúlio Vargas (FGV) e publicitária graduada pela Universidade Municipal de São Caetano do Sul (USCS). E-mail: danuzapessoa@ hotmail.com
} 
Transformar sim, perder a essência jamais: o conto de chapeuzinho vermelho como texto publicitário

de João Batista Freitas Cardoso e Danuza Pessoa Polistchuk

Keyword: advertisement, fairy tale, image, cultural text.

\section{Resumen}

Este estudio tiene como objetivo presentar cómo se pueden reconocer los cuentos de hadas como los códigos culturales, a pesar de los cambios experimentados en el tiempo, mediante el análisis de seis anuncios que tienen el cuento de Caperucita Roja como concepto creativo. A partir de los conceptos de la semiótica rusa y de las teorías de la imagen de Gombrich fue posible reconocer como código el capucha roja y el lobo feroz y mostrar las transformaciones en la narrativa que correspondía a los objetivos de los anunciantes.

Palabras-clave: publicidad, cuentos, imagen, textos culturales.

\section{INTRODUÇÃO}

De modo geral, os contos de fadas e as fábulas são narrativas universais que, ao passarem de geração a geração, transformam-se em códigos culturais. Como códigos de uma dada comunidade, esses contos são reapresentados em diversos produtos culturais: animações, filmes, novelas, livros, histórias em quadrinhos, brinquedos etc. Em cada um desses, as histórias sofrem uma série de mudanças: motivadas pelo contexto político, social e cultural; decorrentes do sistema de codificação integrado pelo próprio produto cultural; ou, ainda, em função da estruturalidade dos sistemas de veiculação e difusão dos produtos culturais (cinema, televisão, propaganda etc). Com o objetivo de difundir as mensagens dos anunciantes e provocar atitude favorável a eles, a propaganda utiliza, na forma de conceito criativo, diversos contos reconhecidos pelo público e que trazem em si uma série de valores simbólicos.

O objetivo deste artigo é investigar como o texto do conto de Chapeuzinho Vermelho, dos Irmãos Grimm, pode ainda ser reconhecido, mesmo assumindo novas estruturalidades. Neste trabalho, entendemos os conceitos de texto e estruturalidade a partir dos estudos de semiótica desenvolvidos por Iuri Lotman (1996). Segundo o autor, todo texto deve ser considerado em função de seu aspecto pragmático, relacionado ao trabalho do texto, "ya que el mecanismo de trabajo del texto supone cierta introducción de algo de fuera en él" (1996:98). Para ele, o que está fora desse texto pode ser: outro texto; o próprio leitor, que é também um texto; ou, até mesmo, o contexto cultural. Esse texto externo é que, na maioria das vezes, trará sentido ao texto impresso. 
Transformar sim, perder a essência jamais: o conto de chapeuzinho vermelho como texto publicitário

de João Batista Freitas Cardoso e Danuza Pessoa Polistchuk

Nas campanhas publicitárias que fazem uso do conto de Chapeuzinho Vermelho, há um texto que vai além da história da menina que leva doces para sua avó. E é justamente esse texto externo que solicita uma nova estruturalidade. A estruturalidade, nesse contexto, "garante a organização de um sistema semiótico como linguagem" (Machado 2003:158), ou seja, no caso do objeto de estudo, permite que o observador rememore o conto ao mesmo tempo em que reconhece o texto como uma mensagem publicitária. Os conceitos de rememoração e reconhecimento serão tratados aqui com base nos estudos de Ernest Gombrich (1993) e Jacques Aumont (2006).

Para compreender o objeto de estudo, serão analisadas quatro peças publicitárias impressas, das marcas O Boticário, Melissa, Campari e Show Off; e dois comerciais de TV das marcas Red Bull e Cremogema, que possuem públicos de interesse variados e veiculação em períodos distintos.

\title{
2. DO TEXTO À REMEMORAÇÃO
}

O conceito de texto, para Lotman, não se aplica apenas às mensagens verbais, mas sim a todo sistema de linguagem portador de sentido, como, por exemplo, uma obra de arte, peça musical, contos ou peça publicitária. Além disso,

\begin{abstract}
[...] el texto se presenta ante nosotros no como la realización de un mensaje en un solo lenguaje cualquiera, sino como un complejo dispositivo que guarda variados códigos, capaz de transformar los mensajes recibidos y de generar nuevos mensajes, un generador informacional que posee rasgos de una persona con un intelecto altamente desarrollado (1996:82).
\end{abstract}

Diante dessa aborgadem, todo texto apresenta ao menos três funções. Primeiro, o texto assume uma função comunicativa, "el 'trabajo' del lenguaje consiste en transmitirle al receptor precisamente el mensaje que transmitió el emisor” (1996:86). Contudo, Lotman chama a atenção para o fato de que, além da função comunicativa, "el texto cumple también uma función formadora de sentido, interviniendo en este caso no en calidad de embalaje pasivo de un sentido dado de antemano, sino como generador de sentido" (1996:87).

A segunda função do texto, para o autor, é a criadora. Nesse caso, não se pode entender um texto por um sentido pré-determinado, mas sim por um sentido gerado. Dessa maneira, não é a linguagem que precede o texto, mas o texto que, uma vez materializado, será o ponto de partida para se compreender a linguagem. 
Transformar sim, perder a essência jamais: o conto de chapeuzinho vermelho como texto publicitário

Así pues, desde el punto de vista de la primera función, es natural representarse el texto como una manifestación de un solo lenguaje [...]. Desde el punto de vista de la segunda función, el texto es heterogéneo y heteroestructural, es un manifestación de vários lenguajes a la vez (Lotman 1996:88).

A terceira função do texto corresponde à manutenção da memória da cultura aspecto que interessa a este trabalho. Nesse caso, os textos são reduzidos a processos mnemotécnicos, tornam-se símbolos integrais de certa cultura e adquirem grande autonomia em seu contexto cultural, funcionando tanto em certo recorte da cultura, quanto em momentos diversos dela. Ao mesmo tempo em que os textos atuam como memória da cultura coletiva, eles são responsáveis por gerar novos textos ao longo tempo, pois estão relacionados a processos dinâmicos e contraditórios. Assim acontece com símbolos que são passados de geração a geração e se transformam em contato com outros textos, sem perderem seus traços originais. É do conflito entre novos textos e a memória coletiva que ocorre a geração de um novo sentido.

De manera análoga podríamos decir que el contacto con outra cultura desempeña el papel de un 'mecanismo de arranque' que pone en marcha procesos generativos. La memoria del hombre que entra em el contacto con el texto, puede ser considerada como un texto complejo, el contacto con el cual conduze a câmbios creadores en la cadena informacional (Lotman 1996:90).

Se na teoria semiótica de Lotman a manutenção de um código ocorre, entre outros fatores, pela memória da cultura, nos estudos das imagens, os conceitos de reconhecimento e rememoração ganham destaque, pois servem para compreender como nos relacionamos com as imagens e como elas nos ajudam a "reforçar, reafirmar e explicitar nossa relação com o mundo visual” (Aumont 2006:81).

Segundo Gombrich (1993:141), "la lectura de la imagen, como la recepción de cualquier otro mensaje, depende del conocimiento previo de las posibilidades; sólo podemos reconocer lo que ya conocemos". Sob essa ótica, o conceito de reconhecimento está ligado à memória e à constância perceptiva das imagens. Quando olhamos uma imagem, buscamos em nossa memória os pontos de similitude com o que já conhecemos anteriormente e assim comparamos a imagem que está em nossa frente com algo semelhante que está em nossa memória. Dessa forma se dá o reconhecimento. Para Gombrich, 
Transformar sim, perder a essência jamais: o conto de chapeuzinho vermelho como texto publicitário

de João Batista Freitas Cardoso e Danuza Pessoa Polistchuk

[...] esse trabalho de reconhecimento, na própria medida em que se trata de reconhecer, apoia-se na memória ou, mais exatamente, em uma reserva de formas de objetos e de arranjos espaciais memorizados: a constância perceptiva é a comparação incessante que fazemos entre o que vemos e o que já vimos (apud Aumont 2006:82).

Somos capazes de reconhecer um rosto apesar das alterações que ele sofre com o passar do tempo, da mesma maneira que somos também capazes de reconhecer uma pessoa por meio de uma caricatura. Nos dois casos, reconhecemos apenas certas invariantes e não todos os elementos visuais que constituem a figura. Na caricatura, por exemplo, o artista reproduz - e intensifica - as invariantes do rosto da pessoa retratada e, mesmo que não tenhamos percebido essas invariantes anteriormente, elas nos auxiliam no processo de reconhecimento. Nesse sentido, como afirma Aumont, "reconhecer não é constatar uma similitude ponto a ponto, é achar invariantes da visão, já estruturados, para alguns, como espécies de grandes formas” (2006:83).

Reconhecer suscita prazer no espectador, e reconhecer algo representado pode proporcionar satisfação psicológica, justamente porque está ligado à rememoração. Assim, quando reconhecemos a imagem de alguém, rememoramos a pessoa e até fatos relacionados a ela.

No que se refere à rememoração, Gombrich afirma que seu instrumento pela imagem pode ser chamado de esquema, que corresponde a uma estrutura simples, de modo sistemático e repetitivo, e que possa ser memoriável. Para que seja memorizado, o esquema deve ser econômico, simples, legível e possuir aspecto cognitivo, ou seja, ele não deve ser absoluto, deve ser integrado por formas que correspondem a certos usos e, geralmente, sofrer alteração e evoluir com o passar do tempo.

Se os traços invariantes de uma dada forma e sua estrutura sistemática permitem o reconhecimento e a rememoração, os traços variantes e as relações complexas entre textos de diferentes origens, como sistemas modelizantes, é que permitirão o surgimento de textos criativos. O pensamento criador, para Lotman, está ligado justamente à capacidade de transformar, por meio de analogias, enunciados de partida (textos originais), por meio de analogias, em textos não previsíveis.

\section{A MODELIZAÇÃO DOS CONTOS EM PRODUTOS MIDIÁTICOS}

Segundo Irene Machado (2003:150), “modelização é a chave para compreender a produção de mensagens resultantes das relações entre as mais variadas linguagens ou 
Transformar sim, perder a essência jamais: o conto de chapeuzinho vermelho como texto publicitário

de João Batista Freitas Cardoso e Danuza Pessoa Polistchuk

os mais variados sistemas semióticos da comunicação social". O processo de modelização, nesse sentido, acontece desde sempre, nas diversas culturas, para que novos textos possam ser compreendidos por determinados grupos.

Por sistemas modelizantes entendem-se as manifestações, práticas ou processos culturais cuja organização depende da transferência de modelos estruturais, tais como aqueles sob os quais se constrói a linguagem natural. Carente de estrutura, o sistema modelizante de segundo grau busca sua estruturalidade na língua, que somente nesse sentido pode ser considerada sistema modelizante de primeiro grau. Assim considerados, todos os sistemas semióticos da cultura são modelizantes uma vez que todos podem correlacionar-se com a língua (Machado 2003:49).

Para Lotman, desde sua origem a cultura se constrói sobre a base de linguagens primárias, como a língua natural, que são responsáveis pela construção das linguagens secundárias. Citando Emile Benveniste, Lótman escreve: "Toda semiología de un sistema no lingüístico debe servirse de la lengua como traductor y sólo puede existir con la ayuda de la semiología de la lengua y dentro de ésta" (1996: 83). Dessa maneira, para o autor, todos os outros sistemas de linguagens são estruturas modelizantes secundárias.

A partir do conceito de modelização é possível entender como determinados textos sofrem alterações em sua estruturalidade, gerando novos textos, em função da codificação de outro sistema. Em outras palavras, como um determinado conto acaba se adequando às especificidades das mais variadas linguagens midiáticas e às particularidades dos contextos relacionados.

Apesar de em nossa sociedade os produtos midiáticos (a literatura, a TV, o cinema, a propaganda etc) contribuírem muito para as modelizações dos contos de fadas, nas civilizações antigas, eslavas e européias, isso já ocorria. Por serem narrativas orais, contadas de grupo para grupo, de tempos em tempos elas sofriam alterações para acompanharem as mudanças culturais e comportamentais dos grupos sociais com os quais tinham contato. Nelly Novaes Coelho, em $O$ conto de fadas - símbolos, mitos, arquétipos, relata que:

Influenciados pelo ideário cristão que se consolidava na época romântica, cedendo à polêmica levantada por alguns intelectuais, contra a crueldade de certos contos, os Grimm ${ }^{3}$, na segunda edição da coletânea, retiraram episódios de demasiada violência ou maldade, principalmente aqueles que eram praticados contra crianças (2012:29).

\footnotetext{
${ }^{3}$ Os irmãos Jacob e Wilhelm Grimm, alemães, filólogos, folcloristas e estudiosos da mitologia germânica, responsáveis por compilar contos que são conhecidos como literatura clássica infantil, como Chapeuzinho Vermelho, A bela adormecida, Branca de Neve e os sete anões, entre outros.
} 
Transformar sim, perder a essência jamais: o conto de chapeuzinho vermelho como texto publicitário

de João Batista Freitas Cardoso e Danuza Pessoa Polistchuk

$\mathrm{Na}$ literatura, não somente os irmãos Grimm, mas também Charles Perrault, poeta e advogado de prestígio na corte francesa, no século XVII, compilou histórias orais que transmitiam noções de ética cristã e comportamento às mulheres, para publicálas em livros, como histórias infantis. Para que pudessem ser lidos por crianças, ele alterou personagens e trechos da narrativa. Desde então, centenas de milhares de livros são recriados e publicados em versões dos contos de Perrault, dos irmãos Grimm e das narrativas orientais, como As 1001 Noites.

No cinema, mais especificamente nas animações, o nome responsável pelo referencial que nossa sociedade tem dos contos é Walt Disney. Seu primeiro desenho animado foi baseado no conto Chapeuzinho Vermelho. Mais tarde, o clássico Branca de Neve e os sete anões ultrapassou todos os recordes de bilheteria da época. Depois desses, vieram muitos outros sucessos de público: A bela e a fera, Cinderela, Aladin etc. Dessa indústria de criações surgiram ainda brinquedos e produtos licenciados. Com o referencial visual dos desenhos da Disney, os contos e seus personagens estampam objetos dos segmentos mais variados.

Além dos Estúdios Disney, outras empresas do campo do entretenimento exploram as temáticas e personagens dos contos de fadas na produção de filmes, brinquedos e serviços de entretenimento, como, por exemplo, a empresa DreamWorks, produtora do longa metragem animado Gato de Botas. Em tal produção, no entanto, a personagem principal apresenta uma série de características visuais e de comportamento diferentes do protagonista do conto original, e contracena com personagens de outros contos, como, por exemplo, Hampty Dumpty, de Mamãe Gansa.

Utilizando a mesma estrutura narrativa, que mistura personagens de diferentes contos de fadas e altera suas características psicológicas e comportamentais, outra produção de sucesso da mesma empresa é Shrek. O casal romântico do filme, Shrek (um ogro) e Fiona (a princesa), não demonstram bons modos como os tradicionais príncipes e princesas das produções Disney. O vilão da história, por sua vez, é justamente o estereótipo do príncipe dos contos de fadas, que representa "o exagero da figura ultrapassada e mal-sucedida" (Amareno \& Chacon 2005: 88).

A indústria cinematográfica também aborda os contos de fadas em diversos filmes. Em Para sempre Cinderela, a gata borralheira aparece juntamente com o os próprios irmãos Grimm e com Leonardo da Vinci. Em A nova Cinderela, o enrredo faz uso de textos da sociedade atual americana. Cinderela é uma jovem que mora com a 
Transformar sim, perder a essência jamais: o conto de chapeuzinho vermelho como texto publicitário

de João Batista Freitas Cardoso e Danuza Pessoa Polistchuk

madrasta e conhece seu príncipe - o aluno mais popular do colégio - pela internet.

Nessa história, em vez de perder o sapatinho de cristal, a jovem perde seu telefone celular.

O filme Branca de Neve e o caçador mantém a estrutura narrativa do conto até o momento em que Branca de Neve foge para a floresta para não ser morta pelo caçador, mas este acaba apaixonando-se por ela e ambos lutam para salvar o reino das mãos da madrasta má. Espelho, espelho meu também mantém parte da estrutura narrativa: a rainha madrasta má, o príncipe e os anões. Contudo: os anões são ladrões; a rainha tenta casar-se com o príncipe rico porque está falida; Branca de Neve deixa de ser indefesa e passa a ser líder dos anões nos roubos; o rei não é morto, e sim enfeitiçado e vira uma fera que é libertada no final.

O conto $A$ bela e a fera foi base para o filme $A$ fera, em que a história se relaciona com o contexto social dos dias atuais. A personagem Chapeuzinho Vermelho também sofre alterações em A garota da capa vermelha. No filme, a personagem é adulta, mas desde a infância é aterrorizada por um lobisomem e não por um lobo-mau. Em João e Maria: caçadores de bruxas, as protagonistas, diferentemente do conto original, também são adultas.

Além de filmes, animações e brinquedos, os contos de fadas também foram apropriados pelos quadrinhos. Na série Grimm Fairy Tales, da editora Zanescope, os contos, mais violentos que os dos livros infantis, são apresentados pela personagem fixa Dra. Sela Mathers. Em Melhores histórias em quadrinhos de conto de fadas, da Editora Globo, as personagens da literatura infantil do Sítio do pica-pau amarelo, de Monteiro Lobato, interagem com personagens dos tradicionais contos de fadas. Emília tenta misturar os contos e seus elementos narrativos para criar novos contos e novas histórias. A turma da Mônica, do cartunista Maurício de Sousa, também se apropriou, diversas vezes, de vários contos de fadas, em seus enredos.

Várias marcas também abordaram os contos de fadas em suas propagandas para comunicar seus posicionamentos e vender produtos e serviços. É o caso da marca de cosméticos O Boticário, que em 2005 estreou a campanha Contos de fadas, apropriando-se dos contos Branca de Neve e o sete anões, Cinderela, Chapeuzinho Vermelho e Rapunzel, em uma abordagem mais madura e sensual. Na próxima seção, serão analisadas seis peças publicitárias de anunciantes de diferentes segmentos que se 
Transformar sim, perder a essência jamais: o conto de chapeuzinho vermelho como texto publicitário

de João Batista Freitas Cardoso e Danuza Pessoa Polistchuk

apropriam do conto Chapeuzinho Vermelho, e alteram a estruturalidade da narrativa, mantendo os códigos que permitem o reconhecimento.

\section{CHAPEUZINHOS VERMELHOS NA PROPAGANDA}

Para compreender como determinados códigos de reconhecimento podem manter-se, apesar da alteração da estruturalidade de um determinado texto, analisaremos as seguintes peças publicitárias: outdoor da campanha Porque já há muitas maneiras de matar a sua idéia (2008), da agência Fuel Lisboa para a produtora de vídeo ShowOff (figura 1); comercial da marca Red Bull (2010), criada pela agência Loducca (http://www.youtube.com/watch?v=id5Gpgcvm-E); comercial para a marca Cremogema (1983), da agência Salles/Interamericana de Publicidade (http://www.youtube.com/watch?v=1S9VOUisGCk); anúncio impresso da campanha Contos de fada, da marca $O$ Boticário (2005), criada pela agência Almap BBDO (figura 2); anúncio impresso da campanha promocional Contos de Campari (2008), criada pela agência francesa Grey Berville Callegary (figura 3); anúncio impresso da campanha Contos de Melissa (2008), criada pela agência BorghiErh/Lowe (figura 4);

Para analisar as peças impressas e os comerciais, será preciso antes identificar os códigos de composição do conto Chapeuzinho Vermelho. Embora o primeiro registro escrito do conto tenha sido feito por Charles Perrault, no século XVII, para a análise deste artigo será utilizada a versão escrita pelos irmãos Grimm, cuja violência é diminuída e tem a inclusão da personagem caçador, aproximando-se mais da referência que temos nos dias atuais. Assim, a história possui os seguintes personagens: Chapeuzinho Vermelho, uma menina doce, meiga, ingênua, que sempre utiliza o capuz vermelho que ganhou da avó; o lobo-mau, maldoso, astuto, esperto e que somente quer comer Chapeuzinho Vermelho e a vovozinha; a vovó, idosa doente, vestida de camisolas, que mora no caminho próximo à floresta; e o caçador, o herói destemido que salva Chapeuzinho Vermelho e avó das garras do lobo, e, em referencial visual, traja um macacão bege com chapéu.

Na versão dos irmãos Grimm, a mãe de Chapeuzinho pede à menina que leve uma cesta com bolo para vovó doente, e diz a ela para que não vá pelo caminho da floresta. A menina desobedece à mãe e desvia-se do caminho. No meio da floresta, o lobo aparece, mas Chapeuzinho Vermelho não tem medo, pois desconhece os perigos 
Transformar sim, perder a essência jamais: o conto de chapeuzinho vermelho como texto publicitário

de João Batista Freitas Cardoso e Danuza Pessoa Polistchuk

que ele pode oferecer. O lobo, então, aproveita- se da ingenuidade da menina e pergunta onde ela está indo e ela responde, sem desconfiar de nada. Ele, que conhecia muito bem os caminhos da floresta, afasta-se rapidamente e chega primeiro à casa da avó de Chapeuzinho, engole a idosa e deita-se na cama, esperando a chegada da menina. Ao chegar, ela bate à porta e ele a manda entrar, fingindo ser a sua avó. A menina percebe que ela está diferente e indaga sobre o tamanho dos olhos, do nariz, da orelha e da boca, quando o lobo diz que ela é grande para comê-la. A menina pede por socorro e um caçador que passava pelas redondezas ouve e corre para ajudá-la. Ele abre a barriga do lobo, tira a vovó e a enche com pedras, causando assim a sua morte.

O conto se passa em três ambientes diferentes: o primeiro é a casa de Chapeuzinho e sua mãe, mas é citado apenas uma vez e tem pouca importância; o segundo é a floresta, descrita com árvores grandes e flores, mas ao mesmo tempo de forma um pouco sombria; e o terceiro é a casa da vovó, que por ser próximo à floresta, é uma casa simples e rudimentar.

Como não poderia deixar de ser, a personagem Chapeuzinho Vermelho é o código que melhor representa o conto nas peças publicitárias. No entanto, embora visualmente, em todas as peças, Chapeuzinho Vermelho seja representada com a capa vermelha, esse elemento é alterado em cada anúncio, em função dos objetivos de comunicação ou imagem da marca.

No anúncio da Show Off, a representação gráfica de Chapeuzinho Vermelho, como no conto dos Irmãos Grimm, é de uma menina frágil, vestindo uma capa vermelha e segurando uma cesta, e sob o risco de ser devorada pelo lobo-mau. Nessa peça é utilizada uma metáfora visual e verbal em que Chapeuzinho Vermelho representa uma ideia para uma campanha publicitária e o lobo-mau, o novo diretor de marketing da empresa, prestes a reprovar tal ideia. A mudança em relação ao enredo de origem ocorre a partir das relações metafóricas, pois, visualmente, a personagem é representada da mesma maneira que aparece nos contos. 
Transformar sim, perder a essência jamais: o conto de chapeuzinho vermelho como texto publicitário

de João Batista Freitas Cardoso e Danuza Pessoa Polistchuk

Fig. 1 - outdoor da Produtora ShowOff

Fonte: http://m619.wordpress.com/2008/12/19/campanha-para-a-produtora-decomerciais-showoff/

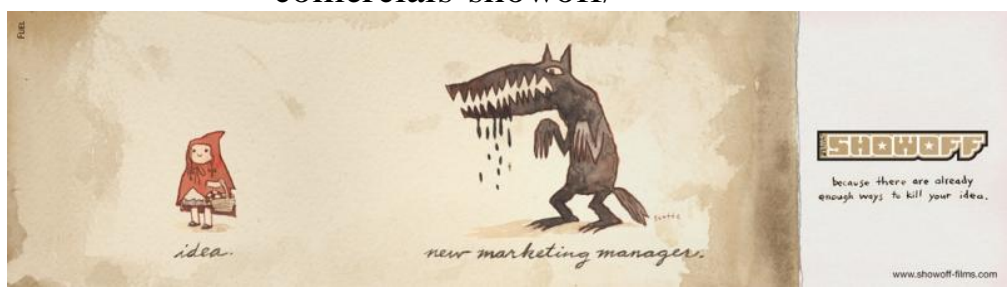

No comercial de Red Bull, da forma como acontece no conto, ela aparece como uma menina que visita a sua avó, levando uma cesta, no entanto, em vez de levar doces, Chapeuzinho leva o produto anunciado, que serve como fonte de energia para a vovó. Mantêm-se, nesse caso, a capa vermelha e a cesta, além da relação com a personagem avó. Porém, alterações são feitas na característica psicológica da menina, que não é mais frágil e inocente, e sim corajosa e, até certo ponto, cruel, pois ambas apresentam-se como caçadoras de lobos.

No comercial de Cremogema, Chapeuzinho Vermelho também se apresenta como uma garotinha aparentemente frágil e levando coisas para a vovozinha, mas, também nessa peça, a garota não é tão ingênua, pois ela dá uma lição de moral no lobomau e faz com que ele mude de comportamento e passe a ser bonzinho para comer Cremogema. A personagem se apresenta então como uma garota corajosa, firme e decidida, como as crianças de nosso tempo. Assim como no comercial do Red Bull, a personagem carrega em sua cesta o produto, que será preparado pela vovó.

Já nos anúncios de $O$ Boticário, Campari e Melissa, Chapeuzinho Vermelho não é mais uma criança frágil e com medo do lobo-mau, ela é uma mulher adulta, madura e que domina o lobo, colocando-o na coleira. No anúncio de Campari, ela aparece em um vestido branco sensual, com a capa vermelha por cima, segurando uma garrafa da bebida, reafirmando sua segurança e seu controle da situação. Na peça de Melissa, Chapeuzinho Vermelho é representada como uma mulher livre, espontânea e que quer se divertir, pois está sentada na garupa da motocicleta do lobo-mau, com uma expressão alegre e vivaz, como uma jovem transgressora.

Tanto as peças impressas, como as eletrônicas apresentam a personagem lobo, o que indica ser esse também um código importante para o processo de reconhecimento do conto. Contudo, em cada uma delas, ele é apresentado de maneira diferente. Em $O$ Boticário, o lobo-mau é apenas citado no título, em uma metáfora que se relaciona diretamente com o público do anúncio: as mulheres de nosso tempo, independentes, 
Transformar sim, perder a essência jamais: o conto de chapeuzinho vermelho como texto publicitário

de João Batista Freitas Cardoso e Danuza Pessoa Polistchuk

mais fortes, decididas e que tomam a iniciativa na relação. Assim, o título do anúncio:

"A história sempre se repete. Toda Chapeuzinho Vermelho que se preze, um belo dia, coloca o lobo mau na coleira", apresenta o lobo-mau de uma nova maneira, como um homem dominado e submisso à mulher Chapeuzinho Vermelho que usa o produto anunciado.

Fig. 2 - anúncio publicitário o Boticário

Fonte: http://ccsp.com.br/ultimas/noticia.php?id=17390

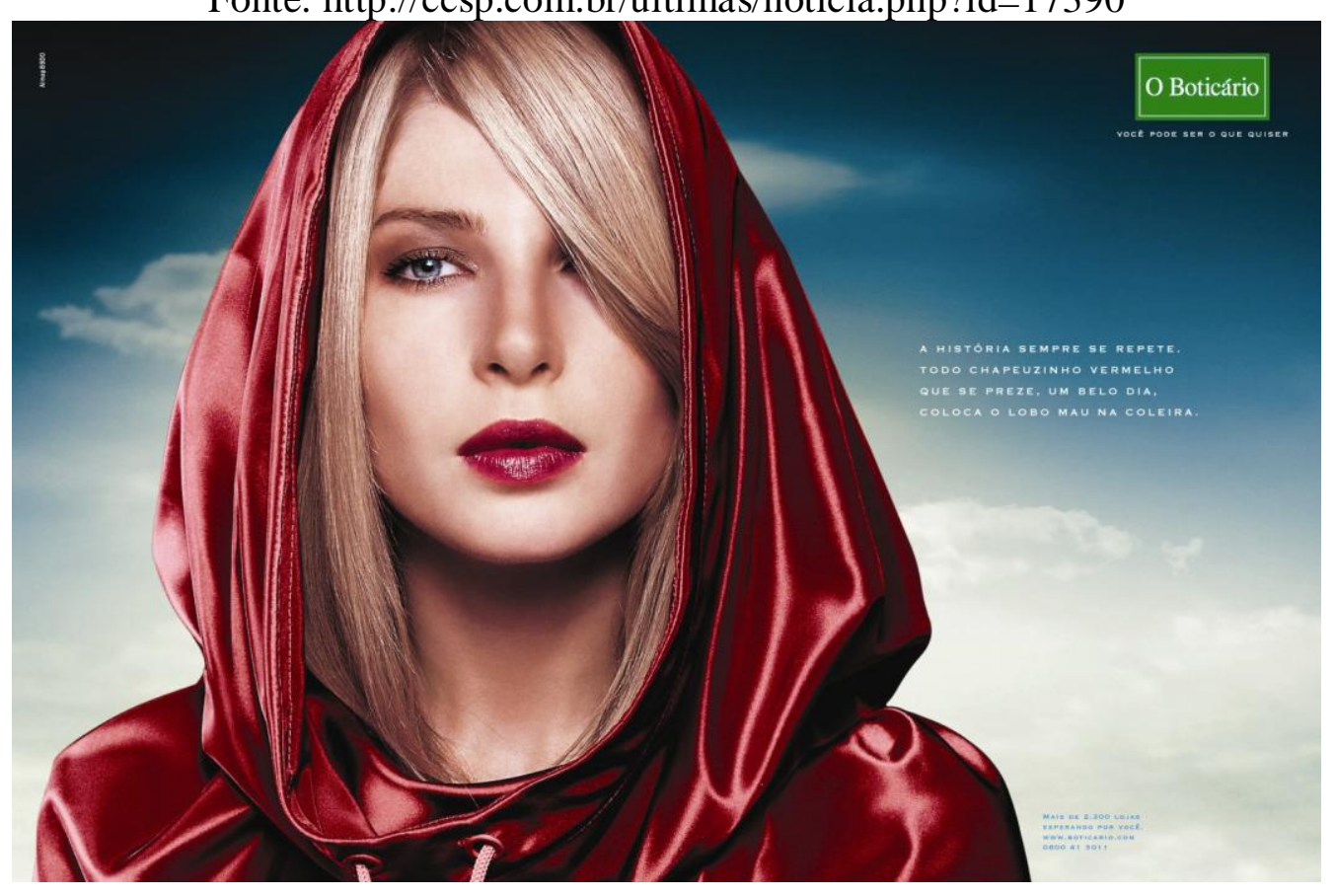

No anúncio da marca Campari, o lobo também aparece dominado pela mulher. No entanto, figurativamente, ele é representado como um animal. Os dentes à mostra revelam sua personalidade feroz, ao mesmo tempo em que Chapeuzinho Vermelho demonstra sua força e personalidade ao conter o animal. 
Transformar sim, perder a essência jamais: o conto de chapeuzinho vermelho como texto publicitário

de João Batista Freitas Cardoso e Danuza Pessoa Polistchuk

Fig. 3 - calendário promocional Campari

Fonte: http://mundofabuloso.blogspot.com.br/2008/03/calendrio-campari-2008-comeva-mendes.html

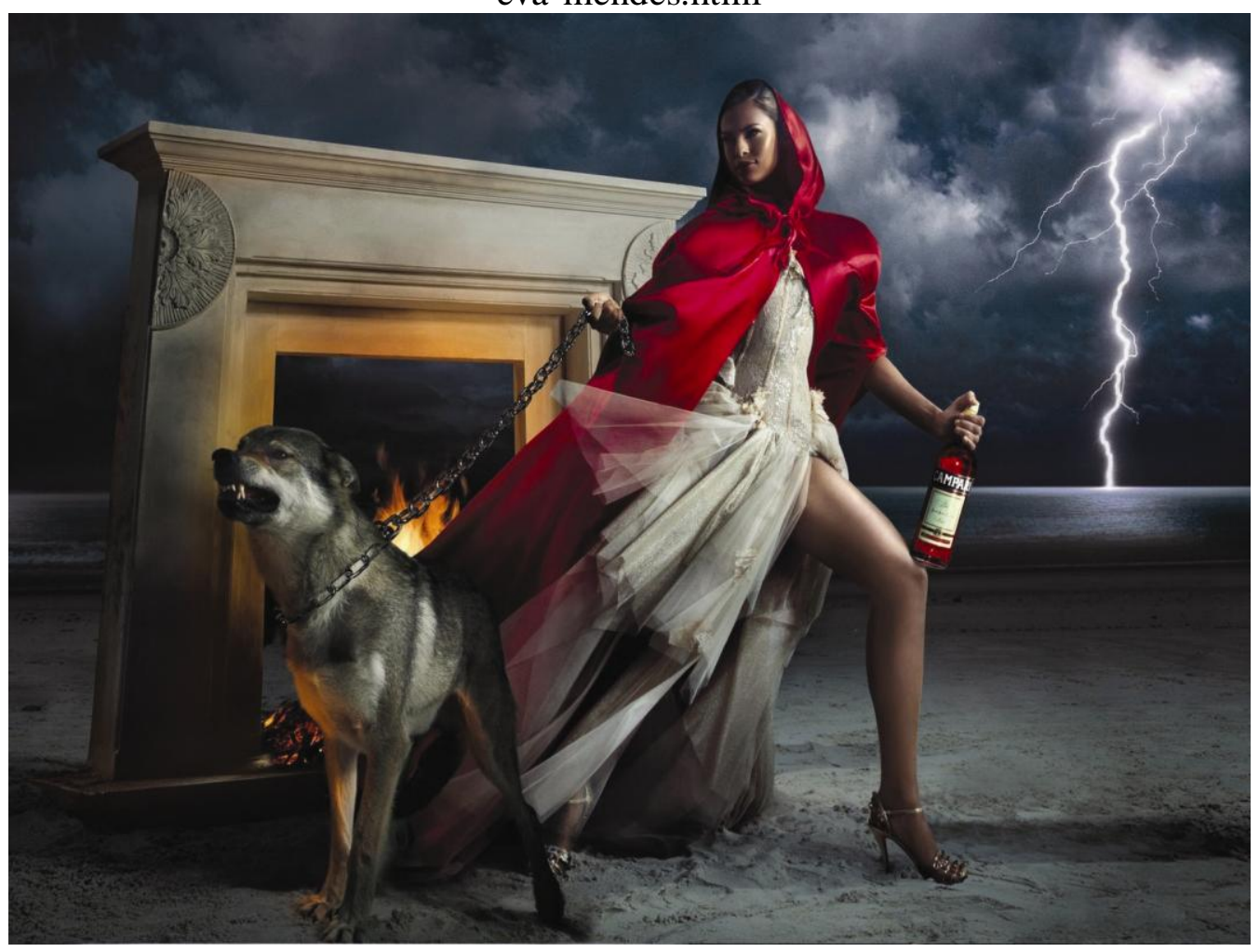

No anúncio da Melissa, ele aparece vestido de jaqueta de couro, pilotando uma motocicleta e levando Chapeuzinho Vermelho na garupa. Apesar de o lobo ser a ilustração de um animal, ele se parece com um rapaz, um jovem disposto a viver uma aventura com uma moça. Embora a peça seja do ano de 2008, as roupas e a forma como os elementos visuais são apresentados rementem aos jovens das décadas de 1950 e 1960, que tinham o rock'n roll e o motociclismo como símbolos de liberdade. 
Transformar sim, perder a essência jamais: o conto de chapeuzinho vermelho como texto publicitário

de João Batista Freitas Cardoso e Danuza Pessoa Polistchuk

Fig.4 - anúncio publicitário Melissa

Fonte: http://mundofabuloso.blogspot.com.br/2007/08/contos-cabulosos.html

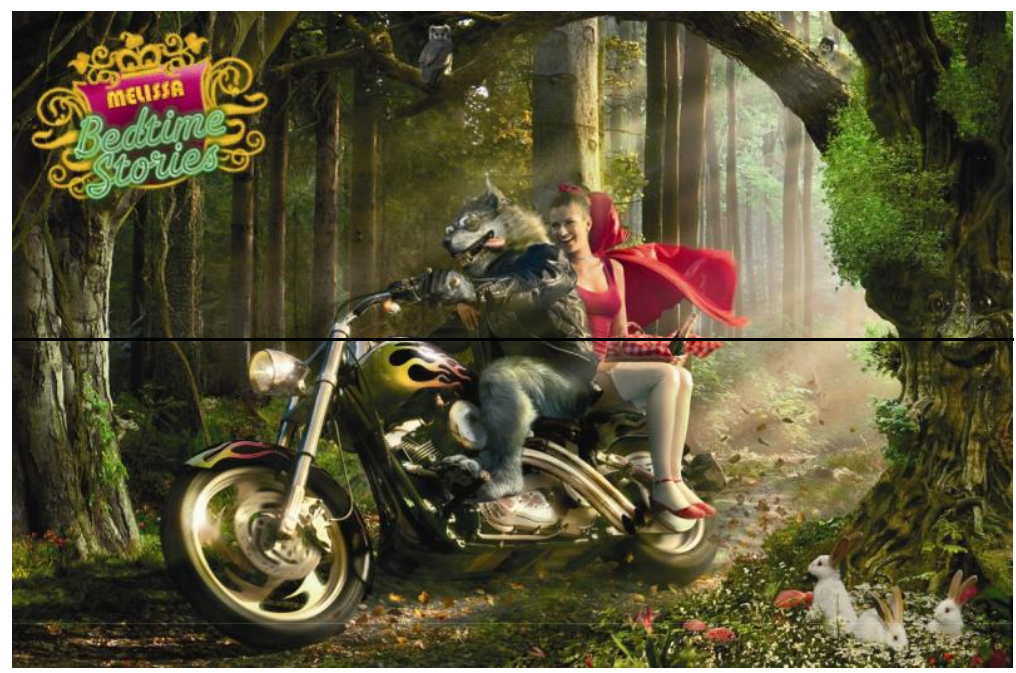

No outdoor da Show Off, o lobo é apresentado visualmente como mau, assim como no conto. A ressignificação, como citado anteriormente, ocorre justamente na metáfora visual e verbal, que transforma o lobo no novo diretor de marketing da empresa que está disposto a destruir Chapeuzinho Vermelho, a ideia para uma campanha publicitária.

Já no comercial de Red Bull, não aparece um único lobo como personagem, mas alguns empalhados na parede e uma pele no chão, ao lado da cama da vovó, servindo de tapete. Há também a citação verbal, na fala da vovó: “[...] então vamos pela estrada a fora caçar mais um lobo-mau”. Assim, reafirma-se que ele deixou de ser o vilão para ser vítima da vovó e da Chapeuzinho, invertendo os papéis quando comparamos ao conto original.

Já no comercial de Cremogema, o lobo, como uma figura teatral, é um homem fantasiado que tenta assustar Chapeuzinho Vermelho. Ele se autointitula como "o lobomau que pega crianças para fazer mingau". Em princípio, a personagem é similar à do conto. Contudo, ao se relacionar com uma Chapeuzinho firme e decidida, que tem Cremogema para fazer mingau, ele, que na verdade não é tão mau assim, muda seu comportamento para comer o mingau preparado pela vovó e não ataca mais ninguém.

As peças impressas apresentam apenas a personagem principal e o lobo, contudo, tanto o comercial de Red Bull, como o de Cremogema apresentam a personagem vovó - no primeiro, como animação, e no outro, interpretado por uma atriz. Ainda que a vovó do comercial de Cremogema seja fisicamente o estereótipo de uma 
Transformar sim, perder a essência jamais: o conto de chapeuzinho vermelho como texto publicitário

de João Batista Freitas Cardoso e Danuza Pessoa Polistchuk

avó - doce e meiga, vestida com xale, broche e coque na cabeça -, nessa produção a

personagem não se encontra doente na cama, ao contrário disso, prepara para as crianças comidas gostosas - imagem que se faz das avós que desejam agradar os seus netos. Considerando apenas essa personagem, pode-se afirmar que dificilmente o público conseguiria reconhecer o conto tendo contato apenas com as cenas em que a avó aparece.

No comercial da Red Bull, por sua vez, temos uma vovó nada convencional: apesar de uma aparência frágil, já que aparece deitada na cama, ela e a neta caçam o lobo-mau, que agora se apresenta como vítima. A alteração da personalidade da personagem e de parte da narrativa se justifica em função da promessa básica do produto: dar mais energia para as atividades do dia a dia. Assim, ao tomar o energético, a frágil vovó ganha mais disposição e vitalidade para caçar o lobo. Nesse caso, a figura da avó na cama, quando aparece em cena, já faz referência ao conto.

A única peça que apresenta o caçador é o comercial de Cremogema, que não exerce a mesma ação do conto dos Irmãos Grimm. Apesar de ser parecido visualmente com o referencial que temos de um caçador, usando macacão e chapéu na cor bege, nessa peça, ele é uma criança que compõe a cena. O caçador não é o herói da história, é apenas um elemento narrativo presente no comercial que dança com as demais personagens. O herói da história é o produto Cremogema, que serve como estímulo para que o lobo mude de comportamento.

Em função das mudanças na narrativa, os cenários também sofrem alterações radicais em algumas peças. Algumas delas apresentam a floresta ou a casa da vovó, ambientes clássicos dos contos dos Irmãos Grimm. Esses ambientes, como no caso do comercial de Cremogema, ajudam a lembrar o espectador que se trata de uma referência ao conto. Contudo, no anúncio de Campari, o cenário apresenta-se como uma praia sombria, com um raio caindo no mar, ao fundo, e com uma lareira atrás de Chapeuzinho e do lobo. Este gera dramaticidade à peça, ao mesmo tempo em que o fogo da lareira ajuda a revelar essa Chapeuzinho dominadora, senhora de si, dona do lobo e forte. Em $O$ Boticário e Show Off, os fundos neutros servem como pano de fundo para os elementos narrativos se sobressaírem, sem oferecer outra complementaridade às peças.

\section{CONSIDERAÇÕES FINAIS}


Transformar sim, perder a essência jamais: o conto de chapeuzinho vermelho como texto publicitário

de João Batista Freitas Cardoso e Danuza Pessoa Polistchuk

Partindo do princípio de que a identificação de invariantes nos permitem reconhecer as formas em função de dados existentes na memória e que essas invariantes permitem manter os códigos de identificação do conto original ainda, que a estruturalidade da história seja alterada, podemos afirmar que o capuz vermelho, elemento que dá nome a personagem e ao conto, de uma maneira ou outra, apresenta-se como um dos principais códigos do conto e transforma o texto Chapeuzinho Vermelho em código cultural. Em todas as culturas nas quais o conto é conhecido, o capuz vermelho é a marca registrada da garota que desobedece a sua mãe e vai pela floresta, levar doces para a vovozinha.

Outra invariante do conto é o lobo, que mesmo passando por mudanças está ligado diretamente ao conflito que marca a narrativa. A história gira sempre em torno desses dois elementos narrativos, que dificilmente são dissociados. Não existe história de Chapeuzinho Vermelho sem o conflito com o lobo-mau. O reconhecimento do conto ocorre justamente porque essas invariantes permanecem sem alteração, em todas as modelizações que o conto sofreu, ao longo dos tempos. A sua permanência e constância faz com essas invariantes transformem-se em código cultural, que, por sua vez, são assimilados e difundidos pelos públicos, e assim propiciam a manutenção da memória e consequente reconhecimento. E é justamente da relação entre os dois que a moral é apresentada, na história original. Por outro lado, é na modelização dessa relação que também nascem outros textos criativos.

Lotman (1996:65) chama de consciência criadora o dispositivo intelectual capaz de gerar novas mensagens. Contudo, toda nova mensagem, para o autor, necessita de algum algoritmo dado de antemão. Para ele, a consciência criadora está intimamente ligada à metáfora, que pertence ao domínio do pensamento analógico (1996:130). "Por eso el estudio de los lenguajes artísticos, y en particular del poético, deja de ser meramente una estrecha esfera de funcionamiento de la lingüística: está en la base de la modelización de los procesos dinámicos del lenguaje" (1998:55). Os sistemas semióticos de informação secundária, provenientes de sistemas de modelização secundários - como são os textos publicitários que se apropriam de textos já existentes - são dinâmicos e necessitam de relações extrasistêmicas para que desempenhem seu papel.

\section{REFERÊNCIAS BIBLIOGRÁFICAS}


Transformar sim, perder a essência jamais: o conto de chapeuzinho vermelho como texto publicitário

AUMONT, J. A imagem. Campinas, SP, Papirus, 2006.

AMERENO, D. S.; CHACON, J. "Shrek e a nova representação dos contos de fadas", in Cenários da Comunicação, São Paulo, v. 4, 2005: 77-98.

COELHO, N. N. O conto de fadas: símbolos, mitos e arquétipos. São Paulo, Paulinas, 2012.

GOMBRICH, E. H. "La imagen visual: su lugar en la comunicación”, in GOMBRICH, E. H. La imagen y el ojo. Madrid, Alianza Editora, 1993: 129-151.

LOTMAN, I. "Un modelo dinámico del sistema semiótico", in NAVARRO, D. (ed.). La semiosfera II - Semiótica de la cultura, del texto, de la conducta y del espacio. Madrid, Ediciones Cátedra, 1998: 43-55.

- "Para la construcción de una teoría de la interacción de las culturas (el aspecto semiótico)" , in NAVARRO, D. (ed.). La semiosfera I - Semiótica de la cultura y del texto. Madrid, Ediciones Cátedra, 1996: 61-76.

. "La Semiótica de la cultura y el concepto de texto", in NAVARRO, D. (ed.). La semiosfera I - Semiótica de la cultura y del texto. Madrid, Ediciones Cátedra, 1996: 77-82.

. "El texto y el poliglotismo de la cultura", in NAVARRO, D. (ed.). La semiosfera I - Semiótica de la cultura y del texto. Madrid, Ediciones Cátedra, 1996: 83-90.

. "La retórica", in NAVARRO, D. (ed.). La semiosfera I - Semiótica de la cultura y del texto. Madrid, Ediciones Cátedra, 1996: 118-142.

MACHADO, I. Escola de semiótica: a experiência de Tártu-Moscou para o estudo da cultura. São Paulo, Ateliê, 2003.

Artigo submetido: 16/03/2013

Artigo aprovado: 28/11/2013 